\title{
Machado de Assis, o outsider estabelecido ${ }^{1}$
}

RICHARD M ISKOLCI*

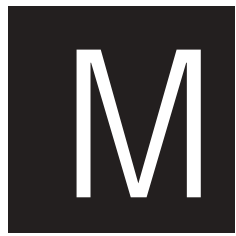

achado de Assis via o intelectual que se apoiava nas novas idéias científicas aspirar a um poder inquestionável e que só compartilharia com seus iguais. A asserção de Simão Bacamarte em 0 Alienista (1882) não deixa dúvidas: “M eus senhores, a ciência é coisa séria, e merece ser tratada com seriedade. Não dou razão dos meus atos de alienista a ninguém, salvo aos mestres e a Deus." (Assis, 1979, p.272) A ironia machadiana utiliza a pretensão dos cientistas de se igualarem a Deus, para fazer uma crítica ao poder que a ciência passara a conferir a seus adeptos no período final do Império.

Machado devotou atenção especial aos nossos intelectuais e às idéias científicas em voga, a partir de seu ensaio sobre a N ova Geração (1879), mas foi na primeira parte da década de 1880 que se esmerou em criaçõesficcionais marcadas pela ironia com relação ao fascínio de seus contemporâneos pela ciência. $O$ criador de Quincas Borba era um dissidente com relação a esse modismo, o que comprova sua polêmica com Silvio Romero, a qual se tornou um dos episódios mais importantes de nossa história intelectual.

* Doutor em Sociologia/U SP, Professor adjunto/U FSCAR. Brasil.

1 Este texto é uma versão aprimorada do artigo que foi apresentado no grupo "Pensamento Social e Literatura da Sociedade Brasileira de Sociologia" (setembro de 2003-U NICAM P). 
A compreensão da polêmica entre Machado e Romero exige reconstituir o período de mudanças pelo qual passou o Brasil a partir da década de 1870. A fundação do Partido Republicano, a Lei do Ventre Livre aprovada em 1871, a crescente importância dos militares após a vitória na Guerra do Paraguai e as reformas estruturais implementadas pelo gabinete Rio Branco criaram as condições para que emergisse uma geração de intelectuais opostos à ordem imperial: a chamada Geração 1870. Esta geração de intelectuais se caracterizava pela oposição à ordem saquarema (do Partido Conservador) que vigorou de forma quase ininterrupta entre 1848 e 1878. A oposição se dava em duas frentes, em termos políticos, os componentes eram abolicionistas e/ou republicanos e, em termos intelectuais, opunham-se aos três pilares da ordem imperial conservadora: o catolicismo hierárquico, o indianismo romântico que definia a nacionalidade de forma estetizada e o regime que limitava a participação política.

Machado de Assis partilhava com os intelectuais desta geração de certa oposição crítica à ordem imperial. Se, na década de 1860, escrevia sob a perspectiva de um liberal, é visível o processo de distanciamento crítico por que passa na década seguinte e que culminaria no divisor de águas de sua obra que foi a publicação em folhetim de M emórias Póstumas de Brás Cubas em 1880. Machado interessava-se pela política e acompanhou atentamente os debates parlamentares da década final do Império. Apesar desse interesse, sua compreensão da literatura era a de um campo em que imperariam considerações estéticas que jamais poderiam ser abandonadas em função de objetivos extraliterários. (Assis, 1946)

Ao contrário de Machado, o interesse político era o que melhor caracterizava os componentes da N ova Geração, os quais são difíceis de reunir como grupo coeso para além dessa classificação geracional. Durante muitas décadas, prevaleceram versões da opinião de Sérgio Buarque de Holanda de que nosso pensamento social nascente caracterizou-se pela fragilidade e 
indiferença ao conjunto social (H olanda, 1990, p.121). D aí a caracterização, feita por Antonio Candido, de seus componentes como "novos ricos da cultura" (Candido, 1988, p.30), a tentativa de Roberto Schwarz de defini-los através de suas idéias políticas aparentemente "fora do lugar", ou ainda os desdobramentos dessa tentativa nos estudos de história cultural de Nicolau Sevcenko, Roberto Ventura e Lilia M oritz Schwarcz, todos marcados pelo esforço de explorar a "originalidade da cópia" que caracterizaria a forma como nossos intelectuais incorporaram as novas idéias científicas. ${ }^{2}$

Recentemente surgiram análises que buscaram lançar um olhar novo sobre a Geração 1870. Entre elas, a de Angela Alonso rompe com tentativas de separar o aspecto político do intelectual na caracterização dessa geração. Segundo a pesquisadora, o caráter unitário do movimento não se assentaria em doutrinas, origem social comum, instituições acadêmicas, mas antes, em uma experiência compartilhada de marginalização política. A longa dominação conservadora bloqueara a estes jovens o acesso às instituições políticas fundamentais e os relegara a um papel de críticos deslocados. (Alonso, 2002)

Silvio Romero foi um dos representantes mais célebres da Geração de 1870. Apesar de sua origem na camada senhorial decadente de Sergipe, o que caracterizava este egresso da Faculdade de Direito do Recife era sua compreensão da vida intelectual como eminentemente política. Por isso, Romero considerava que a ciência devia ser incorporada à literatura, em um projeto de superação do Romantismo e oposição à ordem imperial.

Esta curta exposição sobre um período tão rico da história brasileira serve para contextualizarmos a polêmica entre Romero e M achado de As-

2 Roberto Schwarz lidou com estas questões em seus estudos sobre Machado, sobretudo no ensaio "As Idéias fora do Lugar" que abre Ao Vencedor as Batatas e na análise das teorias científicas e do Humanitismo, no final de Um Mestre na Periferia do Capitalismo. Nicolau Sevcenko fez uma análise sobre a situação de dois intelectuais na Primeira República, Euclides da Cunha e Lima Barreto, em seu livro Literatura como Missão. Roberto Ventura reconstituiu o período de formação de nossa crítica literária através das polêmicas de fins do século XIX, em especial entre Sílvio Romero e Araripe Júnior em Estilo Tropical. Lilia M oritz Schwarcz empreendeu estudos similares, mas abrangendo um espectro maior e menos centrado na literatura, em 0 Espetáculo das Raças e As Barbas do Imperador - Um Monarca nos Trópicos. 
sis. A contenda começou em 1879, quando Machado publicou um ensaio em que criticou o didatismo da poesia da Nova Geração e rechaçou a utilização de teorias científicas na literatura. 0 autor de Memórias Póstumas atribuiu ao naturalismo dos componentes da geração citada um traço intelectual de "otimismo, não só tranqüilo, mas triunfante." (Assis, 1946, p.189) Referia-se assim ao entusiasmo pela teoria da seleção natural, a qual era estendida à sociedade através da leitura do sociólogo mais importante da época, H erbert Spencer: "e assim como a seleção natural dá a vitória aos mais aptos, assim outra lei, a que se poderá chamar seleção social, entregará a palma aos mais puros. É o inverso da tradição bíblica; é o paraíso no fim." (O p. Cit., 190)

M achado classificou a Nova Geração como um movimento de transição (O p. Cit., p. 203) e desferiu críticas ao volume de poesias Cantos do Fim do Século de Silvio Romero. Ele ressaltou a falta de estilo do mestre de Recife, estilo que lembrou ser um dos atributos até mesmo de ídolos científicos de Romero como Darwin e Spencer. Por fim, M achado afirmou que o intelectual sergipano simplesmente não era um poeta, e sua forma ríspida de reagir a críticas era tão deselegante que poderia ser compreendida como sinal de mediocridade.

O Império foi abolido e declarada a República, e, mesmo passados dezoito anos, Silvio Romero não esqueceu as críticas de Machado nem abdicou de suas crenças científicas. No mesmo ano da criação da Academia Brasileira de Letras (1897), tendo como patrono o autor de 0 Alienista, 0 crítico publicou Machado de Assis - Estudo Comparativo de Literatura Brasileira, livro no qual defende a tese de que Machado não era o grande escritor brasileiro, mas sim, Tobias Barreto. Para compreender essa defesa de um representante da Geração 1870 como quem deveria ser alçado ao pódio das letras nacionais, é necessário apresentar a oposição sob a qual se assentam os argumentos de Romero. 
Romero avalia seus colegas intelectuais e os divide em dois tipos, que podem ser bem definidos como homem de ciência e homem de letras. 0 crítico literário considerava Tobias Barreto alguém "esclarecido", sintonizado com as novas idéias científicas e com objetivos políticos de transformação da sociedade brasileira. Ainda segundo Romero, Machado "Antes e acima de tudo é entre nós o mais acabado espécime do homem de letras, no peculiar significado da palavra. (...) O culto da arte sufocou-lhe na alma qualquer paixão deprimente, qualquer partidarismo incômodo e perturbador".(Romero, 1992, p.54) Tal divisão dos intelectuais em dois tipos opostos e qualitativamente diferentes deriva de uma longa tradição do 0 cidente de depreciar o papel dos escritores frente aos homens de ciência. ${ }^{3}$ Apesar de antiga, esta oposição ainda pode auxiliar-nos a compreender como se davam as relações entre nossos intelectuais, assim como destes, com as idéias hegemônicas no fin-de-siècle brasileiro.

Romero compara a obra de Machado com a de Tobias Barreto a partir da metodologia emprestada a $\mathrm{H}$ ippolite Taine que o levou a afirmar:

É mister ir mais além: descortinar o homem atrás do livro e a sociedade através do homem. Cada escritor é um centro de força, além de uma resultante; como centro de força, age como causa e fator de diferenciação e progresso; como resultante, é um efeito de um meio dado, de um grupo social e deve refletir as qualidades do agregado a que pertence. (Romero, $0 \mathrm{p}$. Cit., p.79)

Desta forma, Romero sintetiza seu critério "nacionalístico", aquele que analisaria a importância da obra de um escritor como expressão do que

3 Tal oposição remonta ao Renascimento e se tornou paradigmática na discussão sobre as relações entre ciências biológicas e exatas com as humanidades e a literatura a partir do estudo clássico de C. P. Snow Two Cultures. Na década de 1980, 0 pesquisador alemão Wolf Lepenies discutiu o caráter particular da sociologia entre as ciências e a literatura em As Três Culturas. 
ele considerava o caráter nacional. ${ }^{4}$ Segundo o crítico, Machado de Assis não teria aproveitado as qualidades e defeitos desse caráter. Assim, o autor de Q uincas Borba, além de um mero "homem de letras", não seria suficientemente brasileiro, antes, um homem acima da média, mas o representante de uma sub-raça cruzada, estéril e com problemas na fala, que se transferiram para sua escrita e atropelaram seu estilo.

O critério nacionalista da crítica de Romero já se desqualifica por se basear em fatores externos à obra para avaliar seu valor artístico. De qualquer forma, é esclarecedor sobre o racismo implícito na afirmação de que o "bruxo de Cosme Velho" era pouco brasileiro, um tipo estranho e deslocado nesta paragem tropical do mundo.

U m elitismo mal-encoberto por um verniz cientificista embasa a argumentação de Romero, que é explícito no final do prefácio de seu livro contra Machado quando afirma que o escritor fora mal apreciado e que era necessário colocá-lo em seu lugar, leia-se, no local que caberia a ele na sociedade e literatura brasileiras. Machado, segundo este critério pouco nobre, era um estranho no pódio das letras nacionais devido à sua origem social e racial. Romero afirma que a obra de Machado é "obra de mestiço" (O p. Cit., p.316), mas ainda que assim também o seja a de seu adorado Tobias Barreto, o que torna a de Machado inferior é o fato de que seu pessimismo não faz parte da "psicologia étnica" brasileira, não é expressão do caráter nacional. ${ }^{5}$

A desqualificação do pessimismo de M achado como não sendo parte do caráter brasileiro era uma resposta "científica" à crítica que o escritor

\footnotetext{
4 M arilena Chauí assim define a idéia de "caráter nacional" que marcou a discussão sobre a nação brasileira, ao menos até a década de 1920: “Q uando se acompanha a elaboração ideológica do 'caráter nacional' brasileiro, observa-se que este é sempre algo pleno e completo, seja essa plenitude positiva (como no caso de Afonso Celso, Gilberto Freyre ou Cassiano Ricardo, por exemplo) ou negativa (como no caso de Silvio Romero, M anuel Bonfim ou Paulo Prado, por exemplo). Em outras palavras, quer para louvá-lo, quer para depreciá-lo, o 'caráter nacional'é uma totalidade de traços coerente, fechada e sem lacunas porque constitui uma 'natureza humana' determinada." (Chauí, 2001, p.21)

5 Romero afirma que Taine demonstrara que o humor é característico das raças nórdicas, assim como o pessimismo, segundo Edmund Rod, não é característica étnica, mas uma anomalia. Com relação ao humor de Machado, Romero faz a seguinte
} 
fizera em 1879 ao "otimismo triunfante" da N ova Geração. Romero defendia que o pessimismo de Machado era falso, provavelmente cópia de autores ingleses. Esta afirmação filia Romero às teorias então correntes sobre a falta de originalidade do mestiço, o qual estaria condenado à cópia ou ao ecletismo.

Até hoje permanece como consenso a classificação da perspectiva de M achado sobre sua sociedade através de epítetos negativos: cética, sardônica, sarcástica, pessimista. Ainda que não se possa negar o caráter crítico do olhar machadiano, este não pode ser reduzido a uma idiossincrasia, como fez Romero, nem ser explicado pela personalidade de Machado. Ao nos contentarmos com tais qualificações genéricas desviamo-nos dos fundamentos desta perspectiva para nos contentarmos em retratar o autor de Memórias Póstumas como um gênio infeliz. Assim, recaímos no clichê romântico do artista doentio, o qual se associou a Machado devido à sua condição de mestiço, gago e epilético. ${ }^{6}$

Machado foi criticado por causa de seu pessimismo, que não exprimiria o caráter brasileiro, mas no que repousava seu pessimismo? A não adesão do escritor ao Naturalismo e seu aparente desdém pela ciência da época. $\mathrm{N}$ a verdade, o pessimismo de $\mathrm{M}$ achado era de crítica social e política que era interpretada como ceticismo, traço de caráter, mais ainda, de falta de caráter nacional segundo o critério de Romero.

\footnotetext{
asserção racista para o desqualificar: "Não sei bem ao certo se ele [M achado] é um germano em qualquer grau; não sei se na América do Norte os mestiços, quando falam de si, dizem: nós, os saxônios... Aqui no Brasil a maior prova, a mais característica do humor neles, é quando dizem: nós, os latinos! - É impagável." Romero, O p. Cit, p.166.

6 A recepção brasileira de $M$ achado, ao menos até meados do século XX, foi marcada pelas idéias patológicas sobre 0 artista. O melhor exemplo desta recepção é a obra clínica de Peregrino Júnior intitulada A doença e constituição de M achado de Assis. Porto Alegre: Globo, 1938, mas ecos patologizantes soam até mesmo no excelente e pioneiro estudo biográfico-literário de Lúcia Miguel Pereira Machado de Assis - Estudo Crítico e Biográfico, no qual a autora diversas vezes alude ao "temperamento doentio" (O p. Cit, p.16) do escritor e chega a afirmar: "Para bem entender M achado de Assis, é preciso não esquecer que ele foi um nevropata (...)" (p.17) e mais adiante "Para bem compreendê-lo é preciso não esquecer daquilo que procurou ocultar: da sua origem escura, da sua mulatice, da sua feiúra, da sua doença - do seu drama enfim." (p.18)
} 
Diante de um dissidente que, mesmo que mal compreendido em suas críticas sociais, alcançara notoriedade literária, Romero tornou-se 0 porta-voz de sua geração contra "o burguês prazenteiro condecorado com a ordem da rosa", o tipo mais acabado do "homem de letras". 0 mestre de Recife precisava colocar Machado em seu lugar e, para isso utilizou-se das mesmas teorias ironizadas pelo escritor para descrevê-lo como mestiço anômalo, eclético e infeliz.

Segundo Romero, Machado não tinha conhecimento científico nem paixão política, atributos que ele considerava essenciais no verdadeiro intelectual, ou mais claramente, no homem de ciência que via em Tobias Barreto, em si mesmo e nos outros companheiros da geração de 1870. Por fim, Romero interroga a seus leitores: "Por que motivo pode o autor de Várias $H$ istórias desmentir assim tão flagrantemente as leis do meio, da raça e do momento?" (O p. Cit, p.318) Esta confluência entre meio, raça e história, típica da segunda metade do século XIX, derivava da definição do cidadão nacional através de determinações biológicas, ${ }^{7}$ das quais merecia destaque a raça, categoria fluida, mas que servia para categorizar o suposto caráter nacional como produto de uma herança genética específica. ${ }^{8}$

Machado de Assis rejeitou o essencialismo biologizante que tanto atraía seus contemporâneos e, como afirmou em seu artigo publicado em Nova York em 1873 com o título de Notícia da Atual Literatura Brasileira - Instinto de Nacionalidade: "O que se deve exigir do escritor antes de tudo, é certo sentimento íntimo, que o torne homem do seu tempo e do seu país, ainda quando trate de assuntos remotos no tempo e no espaço."(Assis, p.817) 0

\footnotetext{
7 Para uma discussão sobre a biologização da nacionalidade, especialmente a brasileira, vide meu artigo U ma Brasileira - A Outra História de Julia Mann. Cadernos Pagu. Campinas, n. 20, p. 157-176, 2003.

$8 \mathrm{H}$ oje sabemos que as nações contemporâneas não são coletivos orgânicos associados voluntariamente por vínculos essenciais comuns. Ao contrário, são "comunidades imaginadas", construídas de acordo com a contingência histórica e social. Para uma discussão aprofundada sobre o tema, vide o livro de Benedict Anderson Comunidades Imaginadas; o já clássico estudo de Eric J. Hobsbawm Nações e Nacionalismo desde $\mathbf{1 7 8 0}$ e a compilação de ensaios feita por Homi Bhabha intitulada $\mathrm{N}$ ation and Narration.
} 
mestre carioca observa ainda, ao se dirigir a seus leitores de língua inglesa: “(...) e perguntarei mais se o Hamlet, o Otelo, o Júlio César, a Julieta e Romeu têm alguma coisa com a história inglesa nem com o território britânico, e se, entretanto, Shakespeare não é, além de um gênio universal, um poeta essencialmente inglês." (Assis, sem data, p.817) Apesar da ambigüidade "biológica" do título de seu artigo (Instinto de Nacionalidade), os argumentos de Machado são culturais e históricos, portanto distintos das categorias biológicas e raciais que dominavam as reflexões da Geração 1870 sobre o Brasil e os brasileiros.

\section{As novas idéias e a naturalização das desigualdades sociais}

A questão por trás da polêmica entre Machado de Assise Silvio Romero sobre o papel do intelectual em nossa sociedade ainda é relevante, mas com certeza, não o é nos termos em que o mestre de Recife a apresentava. A oposição homem de ciência versus homem de letras obscurece o que tornava mais problemática a situação de nossos escritores e pensadores, 0 fato de que não existia ainda um campo intelectual autônomo no Brasil. A ausência de autonomia fazia com que nossos intelectuais fossem um misto de cientistas e políticos, pesquisadores e literatos, acadêmicos e missionários, os quais se moviam nos limites impostos por tal hibridez. (Schwarcz, 2000, p.18)

Segundo Nicolau Sevcenko, nossos "mosqueteiros intelectuais" defendiam a atualização da sociedade brasileira com o modo de vida da Europa, a modernização do País, sua integração na ordem internacional e a elevação do nível intelectual da população. O s caminhos propostos para alcançar tais horizontes eram variados, marcados pela idéia de liberalização das iniciativas que deveriam acontecer no ambiente da concorrência e pela ampliação da participação política. Some-se a essas demandasa adoção das 
novas idéias científicas, as quais, a olhos contemporâneos, parecem ingênuas ou por demais deterministas, mas que, na época, tinham como principal resultado lançar estes pensadores no campo do anticlericalismo militante.

A Geração 1870 representou uma reação à ordem imperial, mas não representou uma ruptura completa com seus valores. O s intelectuais-bacharéis lutavam por maior participação política, e foi justamente a constituição de meios e instituições paralelas para sua expressão o que mais os caracterizou. De qualquer forma, esse movimento reformista mantinha, e até mesmo aprofundava, o culto da ciência iniciado com o Segundo Império. Voltava-se contra a idealização romântica do indianismo oficial, mas apenas para afirmar uma nova concepção da nacionalidade baseada nas teorias científicas naturalistas, portanto, só estendendo a influência da ciência às artes. Além disso, mesmo que seus membros fossem abolicionistas, e muitos, republicanos, tendiam a manter intocada a hierarquia racial que caracterizava a estrutura social brasileira.

Não devemos perder de vista o fato de que a entrada das "novas idéias" no Brasil se deu quase concomitantemente com a fundação do Partido Republicano e durante o processo de abolição da escravatura. Neste sentido, a adoção das teorias darwinistas sociais representava uma reação às idéias políticas igualitárias. Tais teorias deterministas reforçavam a crença na naturalidade das desigualdades sociais e desvinculavam nossos liberais de qualquer compromisso democrático.

Roberto Schwarz afirma que a recepção brasileira da nova ciência européia era ultraconservadora e que as idéias científicas aqui "gravitavam segundo uma regra nova, cujas graças, desgraças, ambigüidades e ilusões eram também singulares." (Schwarz, 2000, p.26) Dessa forma, Machado teria ressaltado os ridículos particulares da nossa ciência. (O p. Cit, p.152) Tais ridículos, no entanto, não poderiam ser vistos como tais em fins do século XIX, pois um levantamento das fontes de nossos homens de ciência 
demonstra que estas eram reacionárias já na origem. Ainda que a geração 1870 européia tenha tido relações com o socialismo e nossos intelectuais conhecessem, mas não se tenham interessado por autores como Marx e $\mathrm{N}$ ietzsche, o que deve ser destacado é que havia uma corrente científica hegemônica em termos mundiais, e é a ela que nossos intelectuais se reportam, sobretudo ao darwinismo social e, já na Primeira República, aos seus desdobramentos na criminologia e na eugenia.

A seleção das fontes de nossos homens de ciência é compreensível através do princípio da utilidade das teorias para lidar com as especificidades da sociedade brasileira. (Alonso, 2002) 0 racismo das teorias científicas européias do período tinha origem aristocrática, e se enquadrava perfeitamente no contexto social do Império do Brasil. N ossa elite branca e ilustrada aceitava as teorias que justificavam seus privilégios e, no caso dos intelectuais que se consideravam progressistas e republicanos, essa aceitação implicava um aparente contra-senso. $\mathrm{Na}$ verdade, o liberalismo brasileiro sempre se caracterizou por uma cisão entre princípios liberais e democráti$\cos ^{9}{ }^{9}$ Assim, as elites do Império estabeleceram uma estrutura de poder na qual a afirmação do liberalismo conviveu com a manutenção das desigualdades sociais.

Nossos políticos e intelectuais mesclavam a doutrina liberal com as teorias científicas mais recentes, no intuito único de justificar suas ambições políticas. Esta estratégia destituída de compromisso com a mudança social tinha paralelo com o que ocorria na Europa e nos Estados U nidos na mesma época.

As teorias científicas da segunda parte do século XIX gravitaram em torno da biologia, que se tornara a ciência com poder explicativo maisforte

9 Para um estudo sobre o liberalismo brasileiro em seu caráter autoritário, veja o livro de Sérgio Adorno O s Aprendizes do Poder. No período da Primeira República, Marcos César Alvarez mostra como nossos bacharéis e juristas defendiam a maneira como tratar desigualmente os desiguais, em Bacharéis, Juristas e Criminologistas - A Nova Escola Penal. 
a partir da publicação, por Charles D arwin, de A O rigem das Espécies(1859). Esse livro, curto, simples e de influência duradoura, trouxe consigo um novo padrão epistemológico, que marcou a ciência, a literatura e a política, ao menos até a Segunda Guerra M undial. As nascentes ciências humanas inspiraram-se nele ao compreender a sociedade como um organismo em que comportamentos individuais, que fugiam à norma, caracterizariam casos de anomia, mas a influência mais decisiva das explicações biológicas e evolutivas aconteceu na corrente conhecida como darwinismo social. Esta teve seus expoentes no próprio CharlesD arwin, em seu primo Francis Galton, e no sociólogo Herbert Spencer. ${ }^{10}$

O liberalismo spenceriano é o grande responsável pelas aparentes "incongruências" entre o discurso e as práticas sociais em fins do século XIX. O sociólogo inglês foi o criador das expressões "struggle for existence" (luta pela existência) e "survival of the fittest" (sobrevivência do mais apto), portanto, o artífice de uma teoria social que as descobertas de Darwin pareciam corroborar. A explicação de Spencer para a história da humanidade como uma luta contínua em que sairiam vencedores os mais aptos gerou duas leituras principais: uma confiante na evolução natural, a qual se daria na luta pela existência dentro da estrutura econômica moderna e outra, por assim dizer pessimista, que mesclou as idéias de Spencer com teorias eugênicas, criminológicas e psiquiátricas para advogar formas de intervenção na sociedade que garantissem as melhores condições para que os "aptos" sobrevivessem.

Em toda a Europa, assim como nos Estados U nidos e no Brasil, surgiram diversos livros sobre a necessidade do controle da herança genética

10 Para uma introdução a esta corrente da ciência ocidental, vide o livro de Mike Hawkins Social Darwinism in European and American Thought 1860-1945 - Nature as Model and Nature as Threat., em especial o capítulo sobre Spencer. Sobre o papel da eugenia na construção da categorização raça, e sobretudo, da nação, consulte Stepan, N ancy Leys. The Hour of Eugenics- Race, Gender, and Nation in Latin América. Sobre normalidade e desvio social consulte Miskolci, Richard. Reflexões sobre Normalidade e Desvio Social. Estudos de Sociologia. Araraquara, n.13/14, p.109-126, 2003. 
humana e principalmente sobre as supostas ameaças de degeneração. Essas ameaças estavam em toda forma de comportamento que se desviasse da norma burguesa, mas, sobretudo, na miscigenação, termo criado pela ciência racial norte-americana para desqualificar as uniões entre pessoas de raças diferentes. ${ }^{11}$

Percebe-se que a sociologia nascente se confundia com a Biologia em uma forma de compreensão da sociedade, que resultava tão liberal quanto autoritária. Spencer era contra qualquer forma de intervenção do Estado na sociedade, daí suas ácidas críticas às leis que propunham ajudar os mais pobres. Embora a leitura brasileira do pensador inglês fosse marcada por uma visão intervencionista, ela não rompia com este desdém, ou até mesmo repulsa, aos menos favorecidos. N ossos homens de ciência incorporavam a sociologia spenceriana para justificar as desigualdades sociais e, somando a esta uma concepção autoritária do papel do Estado, desviavam-se de qualquer proposta para a melhora das condições de vida da população. Segundo nossa mescla de evolucionismo com liberalismo autoritário, o mais lógico era atribuir "nosso atraso" ao povo miscigenado e incapaz de desenvolvimento progressivo. As únicas soluções possíveis seriam esperar que este "povo" sucumbisse naturalmente ou constituir uma "verdadeira nação" a partir do incentivo à vinda de imigrantes europeus. ${ }^{12}$

Esta digressão sobre as relações entre o liberalismo brasileiro com as novas idéias mostra que o ceticismo de $M$ achado com relação à nossa elite e aos nossos homens de ciência não foi mero acaso. 0 autor de $O$ Alienista

\footnotetext{
11 É importante salientar que raças não são entidades naturais preexistentes, antes, grupos sociais criados por relações de poder desiguais e práticas discriminatórias. Nancy Leys Stepan afirma que a ciência, particularmente no ramo biológico, criou as fronteiras entre supostas raças, mas essa criação assentada no poder institucional científico e em sua suposta neutralidade foi erodida pela compreensão contemporânea de que a ciência é sempre marcada por interesses sociais, políticos e culturais do momento histórico em que se insere (Cf. Stepan, O p. Cit, p. 136).

12 Este tipo de argumentação determinista que caracterizou a obra de componentes do M ovimento 1870 alcançou seu ápice em O s Sertões de Euclides da Cunha, romance-tratado em que um incidente trágico da história nacional é apresentado segundo as teorias de Taine, Spencer e, de forma ainda pouco estudada, através da teoria do sociólogo darwinista social austríaco Ludwig Gumplowicz e do psicólogo-social inglês M audsley, autor do célebre Le Crime et la Folie, obra lida com interesse não apenas por Euclides, mas também por João do Rio, M achado de Assis, Silvio Romero e até mesmo Lima Barreto.
} 
era um observador mais acurado da sociedade brasileira do que imaginavam seus adversários, e foi justamente por isso que não se deixou encantar pelas teorias evolucionistas e liberais, abraçadas com ardor por nossos homens de ciência. Como observou Antonio Candido, há um "estranho fio social" (Candido, O p. Cit., p.37) na obra de Machado, um senso profundo da estrutura social brasileira e de como se davam nela as relações de poder.

$M$ achado tinha consciência de que a ciência era vista como panacéia pela maioria dos intelectuais brasileiros, devido ao poder que esta outorgava a seus seguidores. ${ }^{13}$ Isso é cristalino em seu conto Evolução no qual o homem, iluminado pelas novas idéias, assumia, através da ciência, um poder que justificava suas ambições políticas. Dessa forma, o compromisso dosque formavam a N ova Geração era com a superação de sua marginalidade política, mas sem um rompimento com a hierarquia racial que vigorava desde a colonização portuguesa. ${ }^{14}$

Chegamos a uma questão crucial. M achado escreveu sobre a sociedade brasileira do Segundo Reinado, a qual era marcada pela hierarquia. A origem de um indivíduo era essencial para seu prestígio, daí a falsificação da origem dos Cubas e a loucura de enobrecimento que atinge Rubião em Q uincas Borba. A própria condição de Machado como artista consagrado era maculada aos olhos da elite brasileira por ele ser um mulato de origem humilde. A ascensão econômica ou em termos culturais não significava adaptação completa à estrutura hierárquica do Império, mas de uma condição paradoxal.

Raymundo Faoro afirma que nossa elite era formada por uma burguesia insegura, que buscava tornar-se nobre e fidalga por todos os meios,

13 Roberto Gomes mostra como Machado lidou com a ciência oitocentista, a partir de uma abordagem do poder que ela conferia a seus guardiões e não, a partir de teorias específicas. Veja seu artigo "O Alienista: loucura, poder e ciência" na revista Tempo Social.

14 Não por acaso, Romero atribui ao mestiço, e disto não escapa nem Tobias Barreto, "essa moléstia da cor, esse mal não definido ainda, que ainda não tem nome, e deve ser uma espécie de nostalgia da alvura, envolta em certa dose de despeito contra os que gozam da superioridade da brancura." Romero, O p. Cit., p. 188-189. Esta moléstia sem nome bem poderia chamar-se hoje, crítica contra uma injustiça social, mas no Brasil finissecular ela ainda era um sinal de inferioridade biológica. 
“pela imaginação, falsificação ou imitação. Sob esta sombra, cresceu o constrangido acatamento a uma aristocracia sem raízes e sem tradição. Burguesia mascarada de nobreza, incerta de suas posses, indefinida no estilo de vida." (Faoro, 2001, p.21) Este é o meio social retratado por M achado, mas seria esta também sua própria condição na sociedade do Segundo Império?

Machado de Assis, um mulato bem sucedido, constituía um paradoxo vivo na sociedade brasileira. Muitos compreenderam esta condição como uma espécie de paradigma da situação do mulato na classe superior brasileira. Emília Viotti da Costa chegou a afirmar, em seu texto sobre o mito da democracia racial no Brasil, ${ }^{15}$ que o escritor carioca não enfrentou o problema da "negritude" e apenas romanceou histórias de homens brancos. Tais observações são parciais, mas, como outras no mesmo estilo, contribuíram para a imagem de Machado como o "antimulato" na expressão de 0 swald de Andrade, ou ainda para a interpretação de sua obra como produto da adaptação à elite nacional e seus interesses. ${ }^{16}$

Com o passar do tempo, análises históricas como as de John Gledson, Kátia M uricy, Raymundo Faoro, Roberto Schwarz e Sidney Chalhoub, provaram a concepção de crítica social que estrutura a obra machadiana. Esses estudos permitem afirmar que o escritor carioca, mesmo mantendo-se fiel à esfera estética, rompeu mais radicalmente com a ordem imperial do que a Geração 1870, ao colocar em xeque aspectos que nossos homens de ciência deixaram intocados: o culto da ciência como panacéia e a hierarquia patriarcal e racial que estruturava a sociedade brasileira.

15 Cf. Costa, 1985, p.248-265.

16 Esta acusação feita a M achado tem relação com o mito de que ele negava sua origem africana e nem mesmo usava a palavra mulato em sua obra ficcional. Lúcia M iguel Pereira desfez esse mito ao observar que, em Pai contra M ãe, por exemplo, Machado repete-a muitas vezes, ainda que seja verdade que o escritor não gostasse de que se referissem a ele como tal. Esta rejeição ao termo mulato é compreensível pelo estigma que traz o termo. Mulato qualifica o mestiço de negro com branco, como o da mistura entre animais, que origina um ser estéril e inferior. Daí o fato apontado por Pereira de que: "Gonçalves Crespo que, escrevendo de Portugal, enumerava entre as afinidades que os uniam, o fato de serem ambos mestiços, deve ter irritado profundamente o correspondente." (Pereira, O p. Cit, p.235-236) Da mesma forma, Emília Viotti da Costa apresenta a observação de Joaquim $\mathrm{N}$ abuco a José Veríssimo de que, em seu artigo póstumo sobre Machado, deveria suprimir o trecho em que o chamava de o mulato Machado de Assis: "Eu não teria chamado o Machado de mulato e penso que nada lhe doeria mais do que esta síntese." (N abuco apud Costa, O p. Cit., p. 258) 
A maioria de nossos homens de ciência utilizava as teorias científicas para justificar uma suposta hierarquia natural que Ihes era favorável, mas relegava largos setores da população brasileira a uma posição inferior. Assim, Romero pôde inferiorizar Machado devido à sua condição de mulato e porque sua obra não representaria o caráter brasileiro. Machado era o "homem de letras", um impostor entre os intelectuais brasileiros, e sua condição mestiça o impediria de ser original. Além disso, a crítica ao fato de que $M$ achado não teve seguidores na literatura nacional mal esconde a crença nas teorias então correntes sobre a esterilidade do mulato. ${ }^{17}$

Por fim, ao esclarecer as relações de poder expressas na oposição de Romero entre homens de ciência e homem de letras, tornamo-nos aptos a explicitar o que realmente distinguia os posicionamentos dos componentes da Geração 1870 e Machado de Assis: o fato de que nossos intelectuaisbacharéis apoiavam-se em teorias científicas novas que justificavam e "naturalizavam" nossas desigualdades sociais, enquanto M achado compreendia esses intelectuais como partícipes de um jogo de poder, sem compromisso com a transformação social nem capazes de perceber o paradoxo de sua própria condição na sociedade brasileira.

\section{0 outsider entre os estabelecidos}

Machado de Assis partilhava, como os componentes da Geração 1870, da condição de ser um intelectual em um país sem universidades nem outras instituições que garantissem um meio intelectual autônomo para suas atividades. Assim, nossos pensadores tinham poucas opções e se tornavam funcionários públicos, caso de Machado, ou disputavam as poucas

17 Cf. Romero, O p. Cit, p.34. A marginalização da arte no fin-de-siècle se deu através de sua compreensão como mera expressão idiossincrática de uma personalidade mórbida. Para um estudo detalhado sobre as associações entre arte e desvio na virada do século XIX para o XX veja o capítulo "Arte e Degeneração" em Miskolci, Richard. Thomas Mann, o Artista Mestiço. 
vagas nas faculdades e colégios imperiais, o que se passou com a maioria dos integrantes da Geração 1870. Nossos intelectuais permaneciam em uma condição de dependência da mesma ordem social que descreviam em seus livros, buscavam analisar e criticar. Por isso, suas atividades se desenvolviam em condições difíceis e até contraproducentes.

À margem do poder, não é de se estranhar que a grande reivindicação da maior parte de nossos intelectuais fosse a de maior participação política. Daí o caráter de pensadores-políticos da Geração 1870, caracterizada pela marginalidade política e pouco preocupada com a marginalidade social. Esta última fora a condição vivida por Machado desde o nascimento, o que o marcou de forma profunda, como atesta a primeira fase de sua obra literária, que tem como temas recorrentes a situação dos agregados, o dilema moral de aceitação da submissão social e o desejo de ascender na rígida estrutura de classes do Império. ${ }^{18}$

A Geração 1870 era formada por estabelecidos socialmente, mas marginalizados em suas aspirações políticas, ao passo que M achado de Assis fora, antes de tudo, um marginalizado em termos sociais, devido à sua origem pobre, sua infância vivida como agregado, seguida pela luta por independência financeira e reconhecimento literário. Ainda que não tenha tido aspirações políticas, isso não o impediu de ser um observador crítico da ordem imperial e seus dissidentes: os homens de ciência que aparecem em suas obras ficcionais durante a primeira parte da década de 1880.

Antes de avançarmos em nossa reflexão sobre a posição de Machado na sociedade brasileira do fin-de-siècle devemos definir claramente as cate-

18 Roberto Schwarz analisou a temática da ascensão social na primeira fase da obra de Machado em Ao Vencedor as Batatas. Entre as constatações do crítico literário, destaca-se a de que o escritor não aceitava a ordem patriarcal que retratou em seus romances, mas tendia a "racionalizá-la", de tal forma que sua crítica era diluída. De qualquer maneira, segundo Schwarz, Machado contribuiu para a criação de um romance realmente brasileiro, ao trazer para o centro das tramas a figura bem nacional daqueles que viviam nas "bordas" das classes privilegiadas, ou seja, os agregados e dependentes em geral. Os homens, e sobretudo as mulheres, livres na ordem escravocrata, são os protagonistas dessas histórias frustradas de ascensão social. Recentemente o historiador Sidney Chalhoub contestou a tese de Schwarz de que Machado estilizara a ordem patriarcal nos romances de sua primeira fase e analisou-os detidamente para demonstrar que, desde o início, a perspectiva crítica dos agregados estruturava as histórias. Veja Chalhoub, Sidney. Machado de Assis, Historiador. 
gorias "estabelecidose marginais" (outsiders). Segundo N orbert Elias, essas categorias são definidoras de identidades relacionais. Aqueles que fazem parte de uma ou outra são ligados por um laço tenso e desigual de interdependência: os estabelecidos formam um grupo que se compreende e é reconhecido como a "boa sociedade", e seu poder deriva do fato de que constituem um modelo moral para os outros, enquanto o outsidernão constitui um grupo social, está fora deles e costuma ser associado ao desvio. Portanto o par de classificações estabelecidos-outsider ilumina relações de poder de uma dimensão social definida por valores como superioridade moral e social, autocompreensão e reconhecimento, pertencimento e exclusão. ${ }^{19}$

M achado de Assis, a despeito de sua origem humilde e sua condição de mestiço, conseguiu ascender socialmente na nada flexível estrutura de classes do Brasil imperial. Ascendeu por mérito intelectual, mas isso não significa que foi plenamente aceito no topo da sociedade. Pesou-lhe, durante toda a vida, sua cor da pele, marca de sua origem nas classes baixase certeza de que sua posição vivia sob a ameaça de desqualificação. No quadro social e político brasileiro marcado pela decadência do Império e pela ascensão das novas idéias, a posição de M achado era especial: ele era, em certo sentido, parte dos estabelecidos devido à sua condição de escritor respeitado, mas, ao mesmo tempo, um outsider devido à sua origem social e racial.

A obra de Machado apresenta um retrato vivo da elite oligárquica e patriarcal da capital do Império, a mesma que ele conheceu de perto, mas da qual jamais fez parte. D istanciava-o não apenas a origem maculada, mas também seus valores e princípios, os quais não podem ser reduzidos à sua classe de origem ou à qual se associou devido ao sucesso. Machado retra-

19 N orbert Elias e John L. Scotson desenvolveram o estudo clássico sobre estas relações de poder a partir de uma pesquisa de cerca de três anos em uma pequena cidade inglesa, a qual foi publicada como Os Estabelecidos e os Outsiders Sociologia das relações de poder a partir de uma pequena comunidade. 
tou a sociedade brasileira de seu tempo através de histórias das desventuras de nossa elite, seus descasos, autoritarismos e brutalidade com relação aos menos favorecidos na escala social. Embora não tenha criado protagonistas das classes menos favorecidas, negros ou mulatos, esta opção não denota falta de consciência com relação às desigualdades raciais, econômicas e políticas. 0 autor de Dom Casmurro alcançou notoriedade justamente por retratar figuras da elite, que eram criticadas de forma sutil o suficiente para que esta mesma classe pudesse ser a grande leitora de seus romances. Assim, a estratégia de centrar suas histórias na elite foi bem-sucedida e não pode ser confundida com a adesão aos valores e idéias das classes altas.

Também seria precipitado atribuir os valores e princípios de M achado a uma filiação atemporal a seus mestres moralistas franceses (Pascal, M ontaigne, Voltaire) ou a uma religiosidade destituída de Igreja. Esta compreensão a-histórica da perspectiva de Machado sobre a sociedade e as questões de seu tempo é tão tentadora quanto questionável, mas se impôs através de um dos estudos mais clássicos sobre o escritor $A$ Pirâmide e 0 Trapézio de Raymundo Faoro, livro que termina com a tese de que faltou a Machado uma visão propriamente sociológica e de que seus livros apresentavam uma crítica moral às vicissitudes de sua época.

Recentemente Alfredo Bosi desenvolveu a observação de Faoro e reconstituiu as leituras jansenistas de Machado, para defini-lo como um herdeiro da vertente cética do Iluminismo. ${ }^{20}$ Esta análise descontextualiza a obra de M achado e obscurece o "estranho fio social" apontado por Antonio Candido em seus livros. 0 autor de Memórias Póstumas realmente não era um sociólogo, mas leu tanto Pascal quanto Spencer e tinha o olhar fincado nas questões de seu tempo. Sua polêmica com a Geração 1870 se estende desde o ensaio "A Nova Geração" (1879), passando por Memórias Póstu-

20 Para a interpretação de Alfredo Bosi consulte seu livro Machado de Assis - 0 enigma do olhar e o volume Machado de Assis da Coleção Folha Explica. 
mas de Brás Cubas (1880 em folhetinse 1881 como romance), 0 Alienista (1882) até Quincas Borba (cuja versão em folhetins data de meados da década de 1880). Estas obras têm como ponto unificador uma questão contemporânea: os debates sobre a sociedade imperial decadente e as novas idéias científicas advogadas por nossos intelectuais.

A melhor prova da contemporaneidade de Machado está no sistema filosófico de Quincas Borba, personagem de dois de seus romances. 0 H umanitismo é uma paródia das teorias cultuadas pelos intelectuais de seu tempo, sobretudo da forma como nossos homens de ciência uniam o evolucionismo de H erbert Spencer com outras fontes, tudo com o objetivo de defender uma ordem estruturada na sobrevivência dos mais aptos. ${ }^{21}$ Não é mero acaso o fato de que tal doutrina tenha aparecido no romance de Machado no mesmo ano em que foi inaugurado o centro positivista brasileiro, ponto de encontro dos adeptos da linha de pensamento que se tornara uma "moda" até mesmo na Escola Politécnica e na Escola M ilitar.

Ao vencedor as batatas, já dizia Q uincas Borba, assim como, de forma similar afirmavam muitos de nossos intelectuais. M achado não deixou de ironizá-los no papel de provedores de justificativa teórica para uma ordem social injusta e que os relegava também a certa marginalidade. Isto é visível no fato de que Q uincas Borba, o próprio inventor do sistema filosófico-científico, é um marginal na elite e termina mal, enlouquecido e solitário, morre na província. Assim Machado ridiculariza as "novas idéias" e se utiliza da loucura como condenação da forma como nossos homens de ciência aderiam a teorias que justificavam desigualdades. Em sua obra, a ciência é analisada como um discurso cuja pseudoneutralidade tinha poderosas implicações sociais e políticas. Machado dissecou essa scientia

21 Segundo as informações providas pelo acervo que restou da biblioteca de Machado, suas fontes para esta criação tão hilária quanto híbrida foram Spencer, Comte e Darwin (Cf. Jobim, 2001). É provável que Machado tenha feito suas leituras mais importantes de Spencer no final da década de 1870. Daí suas referências explícitas ao pensador inglês em $A$ Nova Geração (1879), no conto Evolução e, de forma mais criativa e menos explícita, no H umanitismo de Q uincas Borba. 
brasiliensis de modo a trazer à luz seus objetivos, os quais considerava a encarnação da loucura: justificar e naturalizar as desigualdades sociais.

A própria condição privilegiada de Machado entre os intelectuais brasileiros colocava em xeque as teorias deterministas e darwinistas sociais. Segundo elas, Machado não podia estar onde estava, daí a questão de Silvio Romero sobre como podia o autor de $O$ Alienista negar as leis do meio e da hereditariedade.

M achado não respondeu diretamente aos ataques de Romero. Talvez por ter consciência de que sua obra falara por si ao ter abordado questão crucial, tanto no contexto brasileiro quanto no internacional: como podiam alguns intelectuais defender idéias que serviam para justificar a superioridade e privilégios de uma classe à qual nem eles mesmo eram perfeitamente ajustados? A dissidência de $M$ achado com relação a esses intelectuais revela que o escritor jamais incorreu no erro de se imaginar como parte da elite brasileira, dos estabelecidos, compreendidos como "modelo social".

Romero, assim como a maioria dos membros da chamada Geração 1870, conheceu a marginalidade política e se devotou à luta pela conquista de espaço na arena do poder. M achado, por sua vez, teve como experiência de vida fundamental a marginalidade social. Como observou Faoro: "O pobre mulato que se evadira da miséria, ganhando status, respeito e prestígio, não pode ter a visão do aristocrata decaído, que apela para o bom passado. Sua visão se lança para o futuro, com o realismo de encarar o mundo com resistência e não como reino das idéias." (Faoro, O p. Cit., p.460)

Romero e seus colegas de geração encaravam a sociedade brasileira sob o prisma de excluídos das decisões políticas, mas suas idéias científicas não se voltavam contra a hierarquia que constituía o alicerce de nossa estrutura social. 0 apelo à ordem em nome do progresso unia os marginalizados políticos com os estabelecidos no Império ou na Primeira República. Machado, uma espécie de intruso na elite, desmonta cuidadosamente em 
suas obras esta aliança entre os intelectuais e o poder, a qual permitia identificar o progresso com o sucesso dos vencedores da struggle for existence, a nossa pálida camada dirigente.

A defesa que Romero fazia do intelectual como misto de homem de ciência e político se chocava com a afirmação machadiana da independência da literatura com relação aos objetivos políticos e científicos. Aparentemente Romero era um intelectual politicamente engajado e moderno, e, por sua vez, Machado era apolítico e passadista. Porém uma observação mais atenta mostra que o engajamento pregado por Romero era a teorias deterministas de fundo autoritário, ao passo que a "especialização" defendida por Machado possibilitava uma crítica da ordem social, em especial com relação à flagrante desigualdade em que ela se assentava.

A criação da Academia Brasileira de Letras em 1897 é um fato mais ambíguo do que parece à primeira vista. Até hoje a maioria dos estudiosos afirma que ela representou uma nostalgia da ordem hierárquica imperial, masé necessário refletir também sobre o papel que essa instituição representou na defesa de uma esfera mais autônoma para as letras nacionais. Ao menos até a Primeira República, a literatura brasileira era dominada principalmente por homens de ação com predisposição para a gerência políticoadministrativa: advogados, engenheiros, militares, médicos e diplomatas. (Sevcenko, O p. Cit., p.237) M achado de Assis aspirava a uma independência criativa que permanecia apenas um sonho em sua época, e apenas assim podemos compreender melhor sua afirmação, na abertura da Academia:

Nascida entre graves cuidados de ordem pública, a Academia Brasileira de Letras tem que ser o que são as instituições análogas: uma torre de marfim, onde se acolhem espíritos literários, com a única preocupação literária, e de onde estendendo os olhos para todos os lados, vejam claro e quieto. Homens daqui podem 
escrever páginas de história, mas a história se faz lá fora. (M achado apud Sevcenko, op. cit., p.217)

A independência e o distanciamento do escritor para alcançar uma visão privilegiada de sua época e sociedade se transferiram até mesmo para três dos narradores de seus romances de maturidade: 0 defunto Brás Cubas, o solitário Casmurro e, principalmente, o diplomata aposentado Aires. Ainda que, na ficção, Machado brinque com a parcialidade de visão e, sobretudo, com o ideal de objetividade dos escritores de seus dias, não há como ignorar sua valorização da perspectiva do outsider, daquele que já não participa do jogo social nem crê mais em suas regras. ${ }^{22}$

A partir do exposto, é possível não cair na precipitação de atribuir o posicionamento crítico de Machado quer à sua origem social humilde ou à sua filiação a autores moralistas franceses. Seu ceticismo resultou da reflexão e dissidência consciente com relação ao que residia por trás das idéias hegemônicas: a justificação de uma estrutura social hierárquica fundada no patriarcalismo e, acima de tudo, no racismo. A dissidência de Machado com relação ao liberalismo autoritário de traços darwinista-sociais indica que sua visão do papel do intelectual na sociedade era a daquele que se mantém fiel aos vencidos na luta pela existência, a qual nada tem de natural, antes é produto de condições assimétricas de poder que definem de antemão os vencedores.

Machado desmascarou as idéias evolucionistas, darwinistas-sociais, e especificamente sua mistura brasileira, como meio de celebração de uma elite ínfima de sua própria vitória. Desta forma, construiu sua obra sob a perspectiva do intelectual que não se acomodou a uma posição privilegiada nem aderiu ao discurso da maioria e, graças a esta opção pôde apresentar

22 Kátia Muricy desenvolve esta reflexão em A Razão Cética - Machado de Assis e as Questões de seu Tempo. A pesquisadora empreende uma análise histórica que se desvincula de compreensões da obra de M achado fincadas na psicologia e reforça as relações entre os temas e os personagens de M achado com as mudanças urbanas, culturais e sobretudo de aburguesamento pelo qual passou a sociedade brasileira no fim do século XIX. 
suas críticas ao intelectual orgânico e burocrático em ascensão. Machado de Assis foi seu oposto e ocupa lugar de destaque entre aqueles que fizeram de sua obra uma forma de resistência intelectual.

\section{Referências}

AD O Rn O, Sérgio. Os Aprendizes do Poder. Rio de Janeiro: Paz e Terra, 1988. ALONSO, Ângela. Idéias em Movimento - A Geração 1870 na Crise do Brasil Império. São Paulo: Paz e Terra, 2002.

ALVAREZ, Marcos César. Bacharéis, Juristas e Criminologistas - A Nova Escola Penal. São Paulo: Método, 2003.

ANDERSO N, Benedict. Comunidades Imaginadas. Cidade do México: Fondo de Cultura, 1993.

ASSIS, Joaquim Maria Machado de. O bra Completa. Rio de Janeiro: Aguilar, 1979.

A Nova Geração In: Crítica Literária. Rio de Janeiro: W M Jackson Inc Éditores, 1946.

BHABHA, Homi. Nation and Narration. London: Routledge, 2000.

BOSI, Alfredo. Machado de Assis. Coleção Folha Explica. São Paulo: Folha Publicações, 2003.

. Machado de Assis - O Enigma do Olhar. São Paulo: Ática, 2000.

CANDIDO, Antonio. Esquema de Machado de Assis In: Vários Escritos. São Paulo: Duas Cidades, 1988.

CHALHOUB, Sidney. Machado de Assis, Historiador. São Paulo: Cia das Letras, 2003.

CHAUÍ, Marilena. Brasil - Mito Fundador e Sociedade Autoritária. São Paulo: Editora Fundação Perseu Abramo, 2001. 
COSTA, Emília Viotti da. 0 mito da democracia racial no Brasil. In: Da Monarquia à República: Momentos Decisivos. São Paulo: Brasiliense, 1985.

ELIAS, Norbert \& Scotson, John L. Os Estabelecidos e os 0 utsiders - Sociologia das Relações de Poder a partir de uma Pequena Comunidade. Rio de Janeiro: Jorge Zahar Editor, 2000.

FAO RO, Raymundo. Machado de Assis: A Pirâmide e o Trapézio. Rio de Janeiro: Globo, 2001.

GOMES, Roberto. O Alienista: loucura, poder e ciência. Tempo Social. São Paulo, n.5, p.145-160, 1994.

HAW KINS, Mike. Social Darwinism in European and American Thought 1860-1945 - Nature as a Model and Nature as a Threat. Cambridge: Cambridge U niversity Press, 1998.

HOBSBAW M, Eric J. Nações e Nacionalismo desde 1780. Rio de Janeiro: Paz e Terra, 2002.

HO LAN DA, Sérgio Buarque de. Raízes do Brasil. Rio de Janeiro: José Olympio, 1990.

JO BIM, José Luís. (O rg.) A Biblioteca de Machado de Assis. Rio de Janeiro: Topbooks, 2001.

LEPENIES, Wolf. As Três Culturas. São Paulo: Edusp, 1995.

MISKO LCI, Richard. Reflexões sobre Normalidade e Desvio Social. Estudos de Sociologia. Araraquara, n.13/14, p.109-126, 2003.

. Thomas Mann, o Artista Mestiço. São Paulo: Annablume/FAPESP, 2003.

. Uma Brasileira - A O utra História de Julia Mann. Cadernos Pagu, Campinas, n.20, p.157-176, 2003.

MURICY, Kátia. A Razão Cética - Machado de Assis e as Questões de seu Tempo. São Paulo: Cia das Letras, 1988.

PEREIRA, Lucia Miguel. Machado de Assis - Estudo Crítico e Biográfico. São Paulo: Cia Editora Nacional, 1936. 
RO MERO, Silvio. Machado de Assis - Estudo Comparativo de Literatura Brasileira. Campinas: Editora da UNICAM P, 1992.

SCHW ARCZ, Lilia Moritz. As Barbas do Imperador - Um Monarca nos Trópicos. São Paulo: Cia das Letras, 2000A.

. 0 Espetáculo das Raças. São Paulo: Cia das Letras, 2000

SCHWARZ, Roberto. Ao Vencedor as Batatas. São Paulo: Duas Cidades/Editora $34,2000$.

. Um Mestre na Periferia do Capitalismo. São Paulo: Duas Cidades/ Editora 34, 2000B.

SEVCEN KO, Nicolau. Literatura como Missão. São Paulo: Brasiliense, 1983.

SN OW, C. P. Two Cultures. Cambridge: Cambridge University Press, 1992.

STEPAN, Nancy Leys. The Hour of Eugenics - Race, Gender, and Nation in Latin America. Ithaca: Cornell University Press, 1996.

VENTU RA, Roberto. Estilo Tropical. São Paulo: Cia das Letras, 1988.

\section{Resumo}

0 artigo discute visões distintas sobre o papel do intelectual na sociedade brasileira de fins do século XIX, a partir da polêmica entre Machado de Assis e Silvio Romero. A ênfase está na condição de nossos pensadores em meio à ausência de um campo intelectual autônomo e, em especial, na visão de Machado sobre o intelectual. Concluímos com uma análise da condição de Machado como um outsider estabelecido, posição que marcou sua crítica aos "homens de ciência" e sua resistência às idéias hegemônicas em seu tempo.

Palavras-chave: Machado de Assis, Silvio Romero, Intelectual, Sociedade, Ciência.

Recebido: 28/02/2005

Aceite final: 23/11/2005 


\section{Machado de Assis, the established Outsider}

\section{Richard M iskolci}

The article debates twenty distinct views on the role of intellectuals in Brazilian society in the late $19^{\text {th }}$ century after the controversy between Machado de Assis and Silvio Romero. The emphasis falls on the conditions of our thinkers among the absence of an autonomous intellectual field and especially Machado de Assis' view on intellectuals. We conclude with an analysis of his condition as an established outsider - a position that marked his criticism to "men of science" and his resistance to the hegemonic ideas of hi times.

Key words: Machado de Assis, Silvio Romero, Intelectual, Society, Science 